\title{
La cuantía en la demanda arbitral, un limitante a los derechos de reparación
}

\author{
Carolina Arroyo Aguirre* \\ Leyre Suárez Dávalos** \\ Gabriela Rivadeneira Chacón*** \\ Recibido/Received: 07/08/2018 \\ Aceptado/Accepted: 08/08/2018
}

\begin{abstract}
SUMARIO: 1. Introducción. 2. Evolución histórica de la cuantía como requisito de la demanda en Ecuador. 2.1 Código de Enjuiciamientos en materia Civil (1907). 2.2 Código de Procedimiento Civil (1953). 2.3 Código de Procedimiento Civil (1987). 2.4 Código de Procedimiento Civil (2005). 2.5 Código Orgánico General del Procesos. 3. Sobre la naturaleza jurídica de la cuantía. 4. Ultra petita como vicio de nulidad de laudos arbitrales en la jurisprudencia ecuatoriana. 5. Cuantía: análisis comparado leyes, reglamentos y jurisprudencia. 5.1 La cuantía en la legislación comparada. 5.2 La cuantía en los principales reglamentos de arbitraje. 5.3 Ultra petita como vicio que anula o impide la ejecución de laudos arbitrales. 6. El problema de los costos arbitrales. 7. Conclusiones y soluciones.
\end{abstract}

* Asociada Senior de la firma Andrade Veloz. LL.B y B.A en Administración de Empresas por la Universidad San Francisco de Quito, MLB por Bucerius Law School, WHU Otto Beisheim School of Management. Correo electrónico: carroyo@andradeveloz.com

** Asociada Senior de la firma Andrade Veloz, Profesora de la Universidad San Francisco de Quito, LL.B por la Universidad San Francisco de Quito, LL.M por New York University. Correo electrónico: lsuarez@andradeveloz.com

*** Asociada de la firma Andrade Veloz, LL.B por la Universidad San Francisco de Quito. Correo electrónico: grivadeneira@andradeveloz.com

C. Arroyo, L. SuÁrez y G. Rivadeneira, "La cuantía en la demanda arbitral, un limitante a los derechos de reparación”, Revista Ecuatoriana de Arbitraje, No. 9, 2017. 
Palabras Clave: cuantía, solicitud de arbitraje, ultra petita, vicio de incongruencia, reparación, daños, nulidad de laudo, exceso de poder.

KEYWORDS: quantum, notice of arbitration, ultra petita, incongruence vice, reparation, damages, award annulment, excess of power.

RESUMEN: Este artículo analiza una práctica arbitral común en el Ecuador, por la cual los árbitros limitan los derechos de reparación al monto de la cuantía. Después de una revisión histórica, jurisprudencial y de derecho comparado, se concluye que la fijación de una cuantía exacta es ajena al arbitraje. Además, esta figura no puede implicar una limitación en la indemnización solicitada y que no existe una justificación para esta práctica, desde el punto de vista de la validez ni la ejecutividad del laudo arbitral.

Aвstract: This article analyses a common practice in Ecuadorian arbitration, in which the right to compensation is limited by the amount set as quantum in the claim. After a historic, jurisprudential and comparative law review, the article concludes that fixing an exact quantum is unknown in arbitration. Also, it concludes that this institution may not amount to a limitation in the relief sought and there is no justification for this practice, under a validity or execution of the arbitral award perspective.

\section{INTRODUCCIÓN}

La cuantía es un concepto que ha constado en la legislación procesal civil ecuatoriana desde -al menos-1907. La noción de la cuantía ha ido evolucionando y adquiriendo diversas interpretaciones con el pasar del tiempo y en atención a la ley procesal vigente en un determinado momento. 
Actualmente, al presentar una demanda ante cualquier centro de arbitraje en Ecuador, se debe determinar la cuantía del reclamo, para que así, puedan calcularse los costos administrativos del centro y se dé trámite a la demanda. Sin embargo, este requisito procesal limita a muchos tribunales arbitrales, quienes se ven forzados a otorgar como indemnización un valor que no exceda el monto establecido como cuantía, aun cuando del proceso arbitral o de las pruebas se desprenda que cualquiera de las partes, de acuerdo a sus pretensiones, tienen derecho a una indemnización mayor.

Es evidente que tanto el juez, como los árbitros no pueden otorgar más allá de lo reclamado, pero esto se refiere a la pretensión no a la cuantía. Por ejemplo, si una persona demanda el incumplimiento de un contrato de arrendamiento por falta de restitución de un inmueble, una vez que se ha vencido el plazo, más la indemnización de daños y perjuicios y estima la cuantía en USD \$20,000.00, considerando el canon de arrendamiento de USD \$1,250.00 por 16 meses que estiman tomará el proceso arbitral, plazo en el que su contraparte deberá restituir el inmueble. Sin embargo, el proceso arbitral toma 30 meses y durante la sustanciación del mismo, el demandado no restituye el inmueble.

Entonces, ¿el actor ha renunciado a su derecho de una reparación íntegra que borre todos los efectos del incumplimiento y le deje en la misma posición que se encontraría si no se hubiera producido el ilícito? La respuesta que se debe obtener es definitivamente no, pues el actor reclamó los daños y perjuicios como pretensión, si erró o subestimó la cuantía esto no puede ser interpretado como un limitante al derecho de reparación.

\section{EVOLUCIÓN HISTÓRICA DE LA CUANTÍA COMO REQUISITO DE LA DEMANDA EN ECUADOR}

La cuantía ha sido un criterio empleado para determinar el trámite que se debía dar a los juicios, para limitar la competencia de los jueces en razón de la cuantía y para poder interponer re- 
cursos verticales. En la actualidad, la cuantía sigue siendo un requisito de la demanda, sin embargo, ya no cumple un papel relevante dentro de la tramitación de los juicios.

\subsection{Código de Enjuiciamientos en Materia Civil (1907)}

El Código de Enjuiciamientos en Materia Civil de $1907^{1}$ empleó el concepto de la cuantía para determinar, entre otros: (i) la competencia de los juzgadores; (ii) el tipo de trámite -considerando el monto del reclamo-; (iii) la posibilidad de interponer recursos verticales'; (iv) el monto de las multas, como por ejemplo, por la falta de procuración judicial ${ }^{3}$; (v) establecer las formalida-

1. Decreto Legislativo 0, RA No. 1907, 19/10/1907.

2. Véase, Sentencia de Tercera Instancia, Serie 2, Gaceta Judicial 144, 19/06/1912: “[...] y así, como el capital, materia de la ejecución asciende solo a novecientos sesenta sucres, la sentencia expedida en segunda instancia no es susceptible del recurso de tercera (art. 394, número $3^{\circ}$ del dicho Código)"; Sentencia de Tercera Instancia, Gaceta Judicial 50, 30/06/1931: "La cuantía del presente juicio es la de la obligación demandada, o sea, la de mil sucres, para todos los efectos del pleito, inclusive para el de los recursos de las providencias que en él se ha expedido; sin que tal cuantía puede variar por la de la reconvención, para el último de los indicados efectos. Por tanto, no siendo susceptible del recurso de tercera instancia la sentencia expedida por la Corte Superior de Guayaquil [...]"; Sentencia de Tercera Instancia, Serie 5, Gaceta Judicial 78, 04/04/1933: “[...] fijada la cuantía mediante la determinación hecha por el actor y que no ha sido contradicha por el demandado, a ella debe atenerse para el efecto de los recursos sin que sea del caso atender al valor de la obligación demandada, otra porque este valor no está precisado desde que se exigen los intereses hasta la total cancelación del crédito, ora porque al Juez no le es dado desconocer el acuerdo de las partes sobre la cuantía. Por lo mismo, principiando por declarar que es susceptible del recurso de tercera instancia la providencia venida en grado, [...]"; Voto Salvado: "2. Según el Art. 5. De las Reformas de 28 de octubre de 1925 al Código de Enjuiciamiento Civil, no hay tercera instancia de los decretos y autos interlocutorios de la Corte Superior en las causas cuya cuantía no pase de cinco mil sucres; Para determinar la cuantía, el juez debe atender, ante todo, al importe de lo que se demanda, o sea la prestación que se exige, y solo a falta de este dato, ha de pasar por la cuantía que fije el actor y que no haya sido contradicha por el demandado; pues la determinación de la cuantía por parte de aquel, es un medio supletorio para su estimación, según el artículo 94 del Código citado, y que por lo mismo no puede aceptarse sino cuando falta el principal, esto es, cuando de la demanda o de los documentos con que se la haya propuesto no conste la verdadera cuantía del juicio; $4^{\circ}$ Por lo tanto, en el presente caso, la declaración que el actor hace con respecto a la cuantía no puede prevalecer, por innecesaria y errónea, sobre lo que tocante a ella, a la cuantía, aparece de la misma reclamación que la demanda continúe; y $5^{\circ}$. Es de todo punto gratuita la suposición de que para el cómputo de la cuantía tuvo en cuenta el actor también los intereses posteriores a la fecha de la demanda, y aun cuando así hubiera sido, al juez le habría correspondido corregir este error, respecto del cual, por ser de derecho, no era posible el allanamiento de la otra parte; Sentencia de Tercera Instancia, Serie 5, Gaceta Judicial 161, 26/04/1939: “[...] no hay tercera instancia de las sentencias dictadas por la Corte Superior, en las causas cuya cuantía no pasa de seis mil sucres".

3. Código de Enjuiciamientos en Materia Civil, Art. 51, RA No. 1907, 19/10/1907.

Art. 51. - "Los procuradores deben presentar poder en el juicio en que comparecen como tales, bien al principiar la litis, o antes de la sentencia; pero, si, en cualquier estado del juicio, la otra parte exigiere que lo presenten, serán obligados a ello; y, si no lo hacen, pagarán las costas y perjuicios que hubieren ocasionado, así como una multa de diez a quinientos sucres. Para la imposición de la multa el Juez tomará en cuenta la naturaleza de la causa y su cuantía. [...]". 
des para dar cuenta de la citación ${ }^{4}$ y; (vi) establecer ciertas solemnidades dependiendo del trámite, como por ejemplo, la forma en la que debía otorgarse un poder ${ }^{5}$.

Según este cuerpo legal, los juicios de mayor cuantía eran aquellos que excedían de 200 sucres, mientras que los inferiores a ese monto eran juicios de menor cuantía. Para la determinación de la cuantía debían tenerse en cuenta los intereses ${ }^{6}$ y, en los casos en que no se hubiere fijado la cuantía en la demanda, ni constare de los documentos aparejados a la demanda, el juez debía solicitar de oficio que el actor la determinara ${ }^{7}$.

En este cuerpo legal existían lineamientos para la determinación de la cuantía. Así, por ejemplo, si el reclamo versaba sobre derechos de valor indeterminado, la cuantía se fijaba atendiendo al precio de la cosa sobre la cual recaía el derecho ${ }^{8}$; en reclamos de arrendamiento la cuantía se fijaba en el canon de arrendamiento por un año'.

4. Código de Enjuiciamientos en Materia Civil, N. 3, Art. 104.

Art. 104. - "En el proceso se pondrá diligencia de haberse hecho la citación, la cual será firmada por la parte a quien se haga y por el Secretario Relator, Escribano o Secretario ad hoc de la causa, si se hallare a la parte y el juicio fuere de mayor cuantía; pero si fuere de menor cuantía, la citación será firmada por la parte y por el Juez de la causa. Si la parte no quisiere o no supiere firmar, firmará por ella un testigo. Se expresará la fecha y la hora de la diligencia".

5. Código de Enjuiciamientos en Materia Civil, N. 3, Art. 53.

Art. 53. - "En las causas de mayor cuantía, los poderes se otorgarán con las mismas solemnidades que una escritura pública; y, si no hubiere Escribano, se observará lo dispuesto en la parte final del inciso 2o. del art. 128 de la Ley Orgánica del Poder Judicial”.

6. Código de Enjuiciamientos en Materia Civil, N. 3, Art. 91.

Art. 91. - "Juicio de mayor cuantía es el que versa sobre un asunto que excede de doscientos sucres, en su acción principal; los demás son de menor cuantía. Para fijar la cuantía de la demanda se tomarán en cuenta los intereses líquidos del capital, los que estuvieren pactados en el documento con que se proponga la demanda, y los frutos que también se hubieren liquidado antes de proponerla".

7. Código de Enjuiciamientos en Materia Civil, N. 3, Art. 92.

Art. 92. - "Cuando la cuantía no se hubiere fijado en la demanda, ni constare de los documentos con que se hubiere propuesto, el Juez, de oficio, ordenará al actor que la determine; y el juicio se sustanciará según la cuantía fijada por este, sin perjuicio de que pueda oponerse la excepción de incompetencia por razón de la cuantía, si se hubiere dado un valor distinto a la cosa o al derecho, objeto de la demanda".

8. Código de Enjuiciamientos en Materia Civil, N. 3, Art. 93.

Art. 93. - "Cuando la demanda verse sobre derechos de valor indeterminado, se fijará la cuantía atendiendo al precio de la cosa a que se refieran, y, en caso de duda, se considerará como de mayor cuantía".

9. Código de Enjuiciamientos en Materia Civil, N. 3, Art. 94.

Art. 94. - "En los juicios sobre arrendamientos, la cuantía se determinará por la importancia de la pensión conductiva en un año, o por lo que valga en el tiempo estipulado, si hubiere sido menor". 
En la jurisprudencia también se determinó que la cuantía se utilizaba para fijar la competencia del juzgador en razón de la cuantía:

Son las partes quienes determinan el Juez que ha de conocer del juicio por la razón de la cuantía; pues el demandante la fija autorizado por la ley, y si el demandado no la contradice alegando falta de jurisdicción, queda establecida la competencia del Juzgado de primera instancia, en cualquier estado del juicio, antes de sentencia, en virtud del acuerdo de las partes sobre la referida cuantía $[\ldots]^{10}$.

En un interesante voto salvado se determinó que, aun cuando el Actor no hubiere fijado la cuantía, el juez debía determinarla según los documentos adjuntos; es decir, la jurisprudencia ecuatoriana, desde 1916, ya contemplaba la posibilidad de que los juzgadores atendieren a los documentos de prueba que acompañaban a la demanda para determinar el monto del reclamo:

Los artículos 91, 92, 93 y 94 del Código de enjuiciamientos dan las reglas a que debe sujetarse el Juez para conocer la cuantía de un juicio; $y$, en la presente causa, son aplicables las del artículo 92, según el cual, a no determinarse la cuantía en la demanda, debe estarse a la que aparezca de los documentos con que se la hubiese propuesto ${ }^{11}$.

Este mismo criterio fue adoptado en otras ocasiones:

[...] la prohibición de enajenar, esto es, la cantidad de dos mil sucres, aun cuando el auto afirme en la demanda que la cuantía es indeterminada, por cuanto, para la fijación de ésta hay que atenerse al referido valor del derecho, cuando este valor aparece de los documentos que se funda en la demanda como aparece en el presente caso, y no la cuantía que se hubiere fijado por el demandante ${ }^{12}$.

10. Sentencia de Tercera Instancia, Serie 3, Gaceta Judicial 143, 11/07/1916.

11. Ibídem.

12. Sentencia de Tercera Instancia, Serie 4, Gaceta Judicial 188, 12/06/1924. 
En el mismo sentido, en una sentencia de tercera instancia, la Corte determinó que, atendiendo a las reglas procesales, no era necesario fijar la cuantía de la demanda con absoluta precisión, bastando únicamente enunciar el máximo y el mínimo de lo que se reclamaba para dar oportunidad al demandado de fijar excepciones:

Trabada así la litis, en orden a las demandas principales, se considera: 1o. ninguna de estas señala, cierta, la cantidad fija, determinada cuyo pago se pide por capital, intereses y cambio; pero, si se atiende ora a que la primera, al expresar la cuantía, dice que lo debido por el "Ingenio Rocafuerte" monta a una cantidad mayor de diez y seis mil sucres, no de veinte mil, ora que la segunda reclama el pago de más de doce mil sucres, no puede aceptarse, por falta de esa determinación, lo alegado, a fojas 967 - 972, acerca de la improcedencia de las demandas. En cualquiera de la expresiones usadas en ellas, se encuentra cumplido el número tercero del artículo 99 del Código de enjuiciamientos, el que, tratándose de cantidad, si requiere se la mencione, no precisa, por ello, el que se la determine y fije con toda exactitud matemática: $y$, por lo tanto, observado el número 4o. del mismo artículo, basta, a ese respecto, que se enuncie lo menos y lo más que se demanda, para que así el demandado pueda proponer excepciones, como el Juez, vistas las pruebas, pueda condenar al respectivo pago $[\ldots]^{13}$ (énfasis añadido).

A pesar de esto, esta misma sentencia, limitaba la facultad de los jueces a extender el reclamo a más de lo demandado:

Conforme a los más obvios principios jurídicos, la sentencia condenatoria no puede extenderse, en ningún caso, a más de lo demandado. Fuera de que no pudiendo conocer el demandante lo que había de durar el litigio le era absolutamente imposible calcular la cantidad que en definitiva se le adeudare por intereses. Por estas consideraciones, los suscritos se separan del parecer de la mayoría en lo relativo a la jurisdicción del Tribunal para conocer de la providencia que le ha venido en $\operatorname{grado}^{14}$.

13. Sentencia de Tercera Instancia, Gaceta Judicial 117, 30/03/1916.

14. Ibídem. 
Finalmente, esta facultad del juzgador parecería haber sido reconocida por la Corte de Tercera Instancia, aunque con un voto salvado:

Voto Salvado: "Manuel Ignacio Ramón, al demandar la reforma del testamento de éste y pedir que, en definitiva, se declare que corresponde a la cedente, y por ella al cesionario, la porción de bienes que forma su legítima rigurosa; fijo la cuantía del juicio expresando que ésta pasaba de dos mil sucres y no excedía de cinco mil; cuantía que no fue objetada por la otra parte al contestar la demanda, ni se ha puesto en duda en ningún momento de la causa, y que ha servido de base en el curso del trámite para los efectos de la jurisdicción y de los recursos; y fijación que se halla en el caso del inciso primero del artículo 2o., de las Reformas de 28 de Octubre de 1925 del Código de Enjuiciamiento Civil ya que, si bien la demanda versa sobre un derecho de valor indeterminado, éste se refiere a cosas susceptibles de apreciación, como la cuota legitimaria que reclama el demandante. En consecuencia, y no siendo potestativo a los jueces alterar la cuantía de un juicio; cuando el actor la ha fijado y el demandado se ha convenido expresa o tácitamente con ella; resulta que la del presente juicio está determinada y no puede, en este momento, cambiársela de oficio en indeterminada, para el efecto de que la sentencia expedida por la Corte Superior de Cuenca, siendo, como es, confirmatoria de la de primera y expedida en un juicio cuya cuantía no pasa de cinco mil sucres, fuese susceptible del recurso de tercera instancia. Por tanto, este Tribunal no tiene jurisdicción para conocer del recurso interpuesto por Francisco Carrasco, ni para examinar la validez del proceso $^{15}$ (énfasis añadido).

\subsection{Código de Procedimiento Civil (1953)}

El Código de Procedimiento Civil de 1953, mantuvo la distinción entre juicios de mayor cuantía y juicios de menor cuantía, estableciendo el límite en $\$ 4,000$ sucres para diferenciarlos ${ }^{16}$, con

15. Sentencia de Tercera Instancia, Serie 5, Gaceta Judicial 45, 26/03/1931.

16. Código de Procedimiento Civil, Art. 66, RO Sup. No. 133, 07/02/1953.

Art. 66. - "Juicio de mayor cuantía es el que versa sobre un asunto que vale cuatro mil sucres o más, aunque lo que se reclame sea inferior a esta cantidad; los demás son de menor cuantía. Para fijar la 


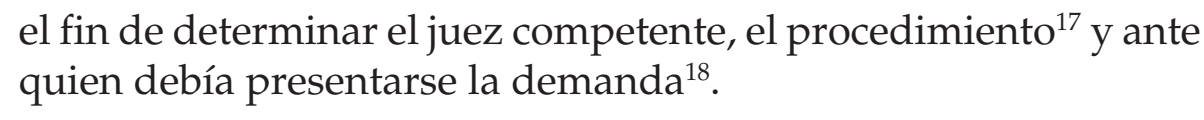

La cuantía debía constar en la demanda o en los documentos aparejados a ella y si no hubiere sido determinada, el juez debía solicitar de oficio que el actor determine la cuantía para poder determinar el juzgador competente en razón de la cuantía ${ }^{19}$.

\section{Para la determinación de la cuantía, en caso de reclamos} sobre derechos de valor indeterminado, debían tenerse en cuenta el precio de las cosas y si esto no pudiera determinarse, se daría el trámite de un juicio de mayor cuantía al reclamo ${ }^{20}$. En caso de reclamos de arrendamiento, la cuantía se determinaría por la importancia de la pensión conductiva de un año ${ }^{21}$ y para los reclamos de alimentos, la cuantía se fijaría atendiendo al máximo de la pensión reclamada por el actor durante un $a \tilde{n} \mathrm{o}^{22}$.

cuantía de la demanda, se tomarán en cuenta los intereses líquidos del capital, los que estuvieren pactados en el documento con que se proponga la demanda, y los frutos que se hubieren liquidado antes de proponerla".

17. Código de Procedimiento Civil, N. 16, Art. 1108.

Art. 1108. - "El Presidente de la Corte Suprema y los de las Cortes Superiores, en las causas civiles de que conozcan en primera instancia, arreglarán el procedimiento a las formas establecidas en este Código, según la cuantía del asunto y la naturaleza de los juicios".

18. Código de Procedimiento Civil, N. 16, Art. 446.

Art. 446. - "Las demandas en los juicios cuya cuantía no pase de doscientos sucres, se presentarán al teniente político respectivo, quien citará al demandado para que conteste dentro de segundo día. Si, citado, no contestare, se resolverá la causa en rebeldía, por las pruebas del actor. Si el demandado propusiere excepciones que deban probarse, o la demanda se fundare en hechos justificables, se concederá el término de tres días para pruebas y tachas. Vencido este término, se pronunciará sentencia. Estos juicios se tramitarán en papel común, formando el correspondiente expedientillo no causarán otros derechos que los de amanuense y sólo de las sentencias se concederá recurso de apelación para ante el juez cantonal, cuyo fallo causará ejecutoria".

19. Código de Procedimiento Civil, N. 16, Art. 67.

Art. 67. - "Cuando la cuantía no consta en la demanda ni en los documentos con que se la haya propuesto, el juez ordenará de oficio que el actor la determine, y sustanciará la causa según la cuantía fijada por éste; sin perjuicio de que pueda oponerse la excepción de incompetencia, por razón de la cuantía, si se hubiere dado un valor distinto a la cosa o al derecho sobre que versa la demanda".

20. Código de Procedimiento Civil, N. 16, Art. 68.

Art. 68. - "Cuando la demanda verse sobre derechos de valor indeterminado que se refieran a cosas susceptibles de apreciación, se fijará la cuantía atendiendo al precio de la cosa o cosas; y si el actor no la fijare, el juez procederá en todo como lo dispone el Art. 67. Si la demanda versa sobre derechos de valor indeterminado a los que no pudiera aplicarse lo dispuesto en el inciso anterior, se ventilará como de mayor cuantía, y, en lo relativo a la concesión de recursos, se considerará como que la cuantía pasa de seis mil sucres".

21. Código de Procedimiento Civil, N. 16, Art. 69.

Art. 69. - "En los juicios provenientes de arrendamiento, la cuantía se determinará por la importancia de la pensión conductiva de un año, o por lo que valga en el tiempo estipulado, si éste fuere menor".

22. Código de Procedimiento Civil, N. 16, Art. 70. 
Al igual que en Código de Enjuiciamiento de 1907, la posibilidad de interponer recursos verticales dependía de la cuantía del reclamo:

Las sentencias en las causas cuya cuantía pase de doscientos sucres, son apelables para ante el juez provincial. El fallo causará ejecutoria en las causas cuya cuantía sea de dos mil sucres o menos; en las demás habrá recurso de tercera instancia para ante la Corte Superior ${ }^{23}$.

El Código de Procedimiento Civil de 1953 determinaba que los laudos arbitrales se ejecutoriarían "dentro de los mismos términos señalados para las de los juzgados comunes, según la naturaleza y cuantía de los pleitos" ${ }^{\prime 2}$. Es en este Código, que se establece que los procedimientos arbitrales, se someterían "en todo" a las disposiciones de los otros juicios, atendiendo su naturaleza y la cuantía:

Los recursos de apelación, en los juicios arbitrales, se someterán en todo a las disposiciones establecidas para los demás juicios, atendiendo a su naturaleza y cuantía; pero, si la causa ha sido juzgada por árbitros arbitradores, podrán los tribunales proceder en su decisión, también como arbitradores ${ }^{25}$.

\subsection{Código de Procedimiento Civil (1987)}

En el Código de Procedimiento Civil de 1987 se estableció claramente que el juez debía sustanciar la causa según la cuantía fijada por el actor y que, para fijar la cuantía de la demanda, "se tomarán en cuenta los intereses líquidos del capital, los que estuvieren pactados en el documento con que se proponga la demanda, y los frutos que se hubieren liquidado antes de proponerla" 26 .

23. Código de Procedimiento Civil, N. 16, Art. 444.

24. Código de Procedimiento Civil, N. 16, Art. 1045.

25. Código de Procedimiento Civil, N. 16, Art. 1054.

26. Código de Procedimiento Civil, N. 16, Arts. 64 y 494.

Art. 494. - "La cuantía se determinará por el valor del capital y los intereses adeudados, según el título con que se demande, sin consideración de los pagos parciales". 
Al igual que en los cuerpos legales precedentes, para fijar la cuantía en caso de cuantías indeterminadas se debía atender al precio de las $\operatorname{cosas}^{27}$, al canon de arrendamiento o el reclamo de la pensión alimenticia. El artículo 71 de este cuerpo legal incluía, como uno de los requisitos de la demanda, la determinación de la cuantía:

La demanda debe ser clara y contendrá:

(...) 5o.- La determinación de la cuantía; (...).

El límite de dos mil sucres servía para determinar ante quien debía proponerse la demanda ${ }^{28}$.

En este cuerpo legal, se estableció que el recurso de apelación en los juicios arbitrales someterá en todo a las disposiciones establecidas para los demás juicios, atendiendo a su naturaleza y cuantía ${ }^{29}$. Este criterio es semejante al contenido en el Código de Procedimiento Civil de 1953.

\subsection{Código de Procedimiento Civil (2005)}

El Código de Procedimiento Civil prescribía que los jueces debían sustanciar la causa de acuerdo a la cuantía ${ }^{30}$. De este modo, si el juicio versaba sobre una obligación que no excediera USD $\$ 20,00$ se trataba de un juicio de ínfima cuantía.

La fijación de la cuantía debía realizarse según las reglas previstas en el Código de Procedimiento Civil. De este modo, cuando la demanda versaba sobre derechos de valor indeterminado que se refieran a cosas susceptibles de apreciación, la cuantía se fijaba de acuerdo al valor de las cosas. Empero, si la demanda trataba sobre derechos de valor indeterminado se consideraba que la cuantía era mayor a USD\$500,00 dólares ${ }^{31}$.

27. Código de Procedimiento Civil, N. 16, Art. 494.

28. Código de Procedimiento Civil, N. 16, Art. 416.

Art. 416: Las demandas, si se trata de juicios cuya cuantía no pase de dos mil sucres, se presentarán ante el juez de lo civil respectivo, quien mandará citar al demandado para que conteste dentro del segundo día; y, Art. 490: Si el juicio ejecutivo versare sobre una obligación que no exceda de dos mil sucres, se observará lo prescrito en los artículos anteriores, procediendo para las actuaciones, en forma prescrita en el Art. 416.

29. Código de Procedimiento Civil, N. 16, Art. 990.

30. Código de Procedimiento Civil, Art. 60, RO Sup. No. 58, 12/07/2005.

31. Código de Procedimiento Civil, N. 30, Art. 61. 
Por otra parte, en los juicios de arrendamiento, la cuantía se fijaba por la pensión conductiva de un año o por lo que valga en el tiempo estipulado si este era menor de un año ${ }^{32}$. En los juicios de alimentos la cuantía debía fijarse sobre el máximo de la pensión reclamada por el actor durante un año ${ }^{33}$.

Por último, cabe mencionar que, según el Código de Procedimiento Civil, uno de los requisitos de la demanda era la determinación de la cuantía ${ }^{34}$, de lo contrario

[...] la demanda será incompleta y caben dos posibilidades: a) que el Juez al calificarla, advierta esta omisión, caso en el cual deberk mandar la complete y si el actor no lo hace en el término señalado por la ley, deberl abstenerse de tramitarla, al tenor de lo que dispone el artículo 73 inciso 3ro. del Código de Procedimiento Civil; y, b) que el Juez incumpla con este deber de velar porque la demanda sea completa y la sustancia, evento en el cual será sancionado por el superior con la multa establecida en el inciso 4 del antes citado artículo $73^{35}$.

\subsection{Código Orgánico General de Procesos}

En el Código Orgánico General de Procesos, a diferencia de los cuerpos legales mencionados anteriormente, la cuantía no es un criterio diferenciador del trámite que se deba dar a cada juicio. Sin embargo, la cuantía aún constituye uno de los requisitos que debe contener la demanda ${ }^{36}$. Adicionalmente, este código contiene reglas específicas para la fijación de la cuantía:

32. Código de Procedimiento Civil, N. 30, Art. 62.

33. Código de Procedimiento Civil, N. 30, Art. 63.

34. Código de Procedimiento Civil, N. 30, Art. 67(5). Véase también, la sentencia dictada por la Corte Nacional de Justicia, Expediente de Casación 410, RO Edición Especial No. 172, 07/07/2011: “De conformidad con lo previsto en el Art. 67, numeral 5 del Código de Procedimiento Civil, uno de los requisitos que debe contener la demanda es la determinación de la cuantía; y una de las formas de cumplir con este requisito, es el determinar cuantía indeterminada. Así mismo según lo dispuesto en el Art. 69 ibídem, corresponde al Juez calificar la demanda, y si es aceptada por reunir los requisitos legales, precluye el momento para exigir el cumplimiento de estos requisitos".

35. Corte Suprema de Justicia, Segunda Sala de lo Civil y Mercantil, Asociación de Productores de Fibra Monterrey v. Compañia Furukawa del Ecuador C.A., 30/05/2007, RO Sup. No. 423, 11/09/2008, pp. 62-63.

36. Código Orgánico General de Procesos (COGEP), Art. 142(10), RO Sup. No. 506, 22/05/2015. 
1. Para fijar la cuantía de la demanda, se tomarán en cuenta los intereses líquidos del capital, los que estén pactados en el documento con que se proponga la demanda y los frutos que se han liquidado antes de proponerla.

2. Cuando la demanda verse sobre derechos de valor indeterminado que se refieran a cosas susceptibles de apreciación, se fijará la cuantía atendiendo el precio de las cosas.

3. En los procesos provenientes de arrendamiento, la cuantía se determinará por el importe de la pensión de un año o por lo que valga en el tiempo estipulado, si este es menor.

4. En los procesos de alimentos se fijará la cuantía atendiendo al máximo de la reclamada por la o el actor durante un año.

5. En materia laboral se cuantificará cada una de las pretensiones de la o del actor para establecer la cuantía.

6. La cuantía será indeterminada únicamente cuando trate de asuntos no apreciables en dinero o que no se encuentren previstos en los incisos anteriores ${ }^{37}$.

En resumen, la cuantía es una figura propia del procedimiento civil, que se estableció como un requisito de la demanda, el cual determinaba la competencia y el procedimiento a seguir. En la actualidad, esta característica de la cuantía ha sido abandonada y la misma se fija, solamente como un requisito de la demanda.

\section{Sobre la Naturaleza Jurídica de la Cuantía}

La cuantía ha sido definida como la cantidad a la que asciende el importe total de lo reclamado en una demanda ${ }^{38}$. Esta figura encuentra un tratamiento efímero y limitado, dentro de los libros de Derecho Procesal, cuando se trata el tema de la competencia de los jueces o como un requisito de la demanda ${ }^{39}$. Así, por ejemplo, ECHANDÍA menciona que: "[1]a mayor o menor importancia económica del negocio opera como factor para determinar

37. COGEP, N. 36, Art. 144.

38. G. Cabanellas, Diccionario Enciclopédico de Derecho Usual, Heliasta, 2008.

39. Véase, por ejemplo, J. Guasp y P. Aragoneses, Derecho Procesal Civil, 5ta Ed., Tomo I, Civitas, 2002, p. 328. 
la competencia del juez que debe conocerlo, de conformidad con el principio de que a menor valor del litigio debe corresponder un menor costo en su composición" ${ }^{\prime 4}$.

Además, este autor reconoce la posibilidad de que se altere la cuantía, ya sea por una reforma a la demanda, o por cualquier circunstancia que aumente o disminuya el valor de lo reclamado. Solo en el primer caso, esta alteración podría conllevar a una pérdida de la competencia del juez ${ }^{41}$; lo cual claramente indica la relación estrecha entre la cuantía y las pretensiones, siendo la primera una estimación de las segundas, pero nunca un limitante.

La cuantía mirada como un elemento para determinar la competencia del juez no tiene ninguna cabida en el arbitraje, donde la competencia de los árbitros nace por el acuerdo de las partes y no tiene relación con el monto reclamado ${ }^{42}$.

Por otra parte, esta figura también ha sido relacionada con los costos en la administración de justicia ${ }^{43}$. Esta segunda noción sí es compatible con el arbitraje, ya que en la cuantía determinada en la demanda arbitral se refleja en los costos arbitrales. Sin embargo, como se explicará más adelante, existen normas que permiten reliquidar los costos arbitrales.

Por lo tanto, la cuantía nació como una figura procesal que permitía determinar la competencia de los jueces y no puede ser interpretada como un límite a la pretensión del actor o reconviniente.

40. D. Echandía, Nociones Generales de Derecho Procesal Civil, Aguilar, 2009, p. 108.

41. D. Echandía, N. 40, p. 110.

42. Existen cláusulas arbitrales que establecen diferentes reglas dependiendo de la cuantía de la disputa, en estos casos, al igual que lo señalado por ECHANDÍA, el tribunal o árbitro único que conozca el proceso no perderá la competencia, si posteriormente se determina que la cuantía es mayor.

43. D. EChAndíA, N. 40, p. 109. "También al Estado debe resultarle más barata la función de administrar justicia en el caso de juicios de inferior valor; por eso conocen de ello jueces de inferior jerarquía y con sueldos menores". 


\section{Ultra Petita Como Vicio de Nulidad de laudos Arbitrales en la Jurisprudencia Ecuatoriana}

La cuantía en el arbitraje local ha sido interpretada como el límite máximo del derecho de reparación del actor o el reconviniente. La principal razón para esto es la observancia al deber de emitir un laudo válido y ejecutable, y el temor a que el laudo sea anulado por un vicio de incongruencia ultra petita. Del análisis realizado en nuestra muestra, se puede concluir que esta práctica de los tribunales arbitrales no responde a lo manifestado por la jurisprudencia ecuatoriana.

En los últimos años se han iniciado numerosas acciones de nulidad de laudos arbitrales bajo el argumento de que el tribunal arbitral incurrió en un vicio de incongruencia al otorgar a una de las partes más de lo que solicitó dentro del proceso arbitral.

Después de realizar un análisis de 41 procesos de nulidad de laudos arbitrales, pudimos concluir que 33 de estas acciones se han fundamentado en la causal prevista en el literal d) del artículo 31 de la LAM, la cual establece que se podrá intentar la acción de nulidad cuando: "[...] el laudo se refiera a cuestiones no sometidas a arbitraje o conceda más allá de lo reclamado". No obstante, de los 33 casos que se han fundamentado en esta causa, únicamente en seis de ellos se han basado en el vicio de incongruencia ultra petita.

Los principales argumentos que se han utilizado para fundamentar una acción de nulidad de laudo por el vicio de incongruencia ultra petita son: (i) en el contexto de un contrato de arrendamiento, se ordenó el reembolso de los costos de servicios básicos, fondos de garantías, costos de arbitraje y honorario de abogados, cuando estos pagos no estaban a consideración del tribunall4; (ii) se limitó la reclamación por concepto de intereses a un monto específico y el tribunal arbitral excedió dicho monto ${ }^{45}$; (iii) el tribunal arbitral ordenó el pago de ciertas facturas más in-

\footnotetext{
44. Véase, Proceso No. 17100-2014-0078.

45. Véase, Proceso No. 17100-2015-0007.
} 
tereses por mora, las cuales no fueron solicitadas dentro del proceso arbitral ${ }^{46}$; (iv) el monto al que ascendían los daños y perjuicios se elevaron debido a que el tribunal arbitral consideró algunas facturas, cuyo valor no era parte de la pretensión ${ }^{47} ;(\mathbf{v})$ el tribunal concedió el reembolso del pago de un anticipo sin que exista en el contrato de promesa de compraventa una cláusula que les faculte a hacerlo ${ }^{48}$ y; (vi) el tribunal arbitral condenó a la parte demandada al pago de un valor superior al fijado por la demandante por concepto de pago de planillas ${ }^{49}$.

Todos los argumentos presentados han sido desechados, principalmente porque se ha considerado que en la mayoría de los casos los tribunales arbitrales han resuelto analizando las pretensiones, excepciones y pruebas que han sido presentadas por las partes dentro del proceso arbitral y que, por lo tanto, no existe vicio de incongruencia ultra petita cuando el tribunal resuelve sobre la materia con la que se trabó la litis.

Específicamente, respecto al pago de intereses, la Corte ha manifestado: "[...] el Tribunal Arbitral no se ha concedido más del monto fijado por la parte actora, por el contrario, se ha limitado a aplicar la ley sobre el monto de intereses por mora, que es parte del contexto total de la cuantía de la demanda"50.

Como se puede evidenciar, las cortes ecuatorianas se han negado a declarar la nulidad de laudos arbitrales por el vicio de incongruencia ultra petita. De hecho, no se declaró la nulidad del laudo arbitral en ninguno de los seis casos mencionados. Por lo expuesto, es claro que limitar los derechos del accionante al valor fijado en la cuantía de la demanda o reconvención, no tiene justificación en el deber de los árbitros de emitir laudos válidos y ejecutables.

\footnotetext{
46. Véase, Proceso No. 17100-2016-00011.

47. Véase, Proceso No. 17113-2014-1296.

48. Véase, Proceso No. 17100-2017-00047.

49. Véase, Proceso No. 17100-2017-0015.

50. Proceso No. 17100-2014-0078, 15/06/2016. Véase tambien, Procesos No. 17100-2014-0078; 17100 2015-0007; 17100-2016-00011; 17113-2014-1296; 17100-2017-00047; y 17100-2017-0015.
} 


\section{Cuantía, Análisis Comparado, leyes, Regla- MENTOS Y JURISPRUDENCIA}

La determinación de la cuantía en los procesos arbitrales, en otras jurisdicciones, no tiene ninguna relevancia. De un análisis de derecho comparado, se puede concluir que, en la gran mayoría de legislación y reglamentos de arbitraje, la determinación de la cuantía no es un requisito para iniciar un arbitraje. Además, en la revisión jurisprudencial no se ha encontrado un fallo arbitral que haya sido anulado o se haya negado su reconocimiento y ejecución porque el Tribunal Arbitral otorgó una cuantía distinta a la solicitada.

\subsection{La cuantía en la legislación comparada}

La Ley Modelo de la Comisión de las Naciones Unidas para el Derecho Mercantil Internacional (CNUDMI), que ha sido acogida por 80 estados y 111 jurisdicciones ${ }^{51}$, establece un esquema -que es la regla en el arbitraje internacional- por el cual, el arbitraje no inicia con la presentación de una demanda, sino que esta se presenta posteriormente.

El artículo 23 de la Ley Modelo de la CNUDMI regula el contenido de la demanda y contestación arbitral, sin mencionar a la cuantía como un requisito ${ }^{52}$. Asimismo, las leyes de arbitraje de Estados Unidos ${ }^{53}$, Francia ${ }^{54}$ y del Reino Unido ${ }^{55}$, tres de las juris-

51. Comisión de las Naciones Unidas para el Derecho Mercantil Internacional (CNUDMI). Situación actual: Ley Modelo de la CNUDMI sobre Arbitraje Comercial Internacional, 1985, con enmiendas adoptadas en 2006, $<$ http://www.uncitral.org/uncitral/es/uncitral_texts/arbitration/1985Model_arbitration_status.html $>$.

52. Ley Modelo de la CNUDMI (1985), Art. 23.

Art. 23. - "Demanda y contestación. - 1) Dentro del plazo convenido por las partes o determinado por el tribunal arbitral, el demandante deberá alegar los hechos en que se funda la demanda, los puntos controvertidos y el objeto de la demanda, y el demandado deberá responder a los extremos alegados en la demanda, a menos que las partes hayan acordado otra cosa respecto de los elementos que la demanda y la contestación deban necesariamente contener. Las partes podrán aportar, al formular sus alegaciones, todos los documentos que consideren pertinentes o hacer referencia a los documentos $\mathrm{u}$ otras pruebas que vayan a presentar [...]".

53. Véase, Ley de Arbitraje Federal, 12/02/1925.

54. Véase, Decreto No. 2011-48, 13/01/2011.

55. Véase, Ley de Arbitraje, 1996. 
dicciones más prominentes en temas arbitrales, no contienen disposiciones que regulen el contenido de la demanda arbitral y otorgan libertad a los árbitros para fijar las normas de procedimiento y amplios poderes al respecto.

\subsection{La cuantía en los principales reglamentos de arbitraje}

Los principales reglamentos internacionales de arbitraje no establecen la fijación de una cuantía exacta para iniciar un arbitraje. Los reglamentos exigen únicamente un estimado del monto a que ascienden los reclamos planteados. Por lo tanto, la fijación de una cuantía exacta es en general ajena en las instituciones que manejan el mayor número de arbitrajes en el mundo.

Para citar algunos ejemplos, el Reglamento de Arbitraje de la CNUDMI, también conocido como reglas UNCITRAL, establece como un requisito que debe contener la notificación de arbitraje "[u]na breve descripción de la controversia y, si procede, una indicación de la suma reclamada"56. También, el Reglamento de Arbitraje de la Cámara de Comercio Internacional (CCI) en su artículo 1 establece los requisitos que debe contener la solicitud de arbitraje, entre ellos se señala como literal d) la pretensión, junto con el monto de cualquier reclamo cuantificable y en la medida de lo posible, un monto estimado del valor de otros recla$\operatorname{mos}^{57}$.

El Reglamento de Arbitraje de la Corte Internacional de Arbitraje de Londres (LCIA), por su parte, establece algo similar a

56. Reglamento de Arbitraje de la CNUDMI, Art. 3(3).

Art. 3(3). - "La notificación del arbitraje contendrá la siguiente información: a) Una petición de que el litigio se someta a arbitraje; b) El nombre y los datos de contacto de las partes; c) Una especificación del acuerdo de arbitraje que se invoca; d) Una especificación de todo contrato u otro instrumento jurídico que haya suscitado o al que se refiera el litigio o, a falta de ese contrato o de otro instrumento jurídico, una breve descripción de la relación controvertida; e) Una breve descripción de la controversia $\mathrm{y}$, si procede, una indicación de la suma reclamada; f) La materia u objeto que se demandan; g) Una propuesta acerca del número de árbitros, el idioma y el lugar del arbitraje, cuando las partes no hayan convenido antes en ello".

57. Reglamento de Arbitraje de la Cámara de Comercio Internacional, Art. 1(3).

Art. 1(3). - "The Request shall contain the following information: [...] d) a statement of the relief sought, together with the amounts of any quantified claims and, to the extent possible, an estimate of the monetary value of any other claims; [...]". 
la CCI, la solicitud de arbitraje deberá describir brevemente la naturaleza y circunstancias de la disputa, su monto o valor estimado, la transacción en cuestión y los reclamos en contra de cada uno de los demandados ${ }^{58}$. De igual manera, la Corte Internacional de Arbitraje de Singapur en su Reglamento de Arbitraje requiere únicamente una cuantificación inicial del monto del reclamo, si esto es posible $\mathrm{e}^{59}$.

De lo expuesto se desprende que determinar de manera exacta la cuantía no es un requisito que deba contener la solicitud de arbitraje. Como es razonable, los reglamentos de arbitraje de los centros más reconocidos en la materia, solicitan al demandante, solamente y si es posible, estimar la cuantía de su demanda, sin que la falta de determinación sea un motivo para no aceptar a trámite la solicitud de arbitraje y mucho menos, se interpreta a esta estimación como un limitante a su derecho de reparación.

\subsection{Ultra petita como vicio que anula o impide la ejecución de laudos arbitrales}

La práctica arbitral ecuatoriana, como se mencionó anteriormente, ve a la fijación de la cuantía como un limitante en la reparación que pueden otorgar al demandante, porque existe el temor de que el laudo arbitral sea anulado, temor que no tiene fundamentación en la jurisprudencia ecuatoriana. En esta sección se demostrará que, desde el punto de vista del derecho comparado, este temor es de igual manera, francamente infundado.

58. Reglamento de arbitraje de la Corte Internacional de Arbitraje de Londres, Art. 1(1).

Art. 1(1). - "Any party wishing to commence an arbitration under the LCIA Rules (the 'Claimant') shall deliver to the Registrar of the LCIA Court (the 'Registrar') a written request for arbitration (the 'Request'), containing or accompanied by: [...] (iii) a statement briefly summarising the nature and circumstances of the dispute, its estimated monetary amount or value, the transaction(s) at issue and the claim advanced by the Claimant against any other party to the arbitration (each such other party being here separately described as a 'Respondent') [...]'.

59. Reglamento de Arbitraje de la Corte Internacional de Arbitraje de Singapur, Regla 3(1). Regla 3(1). - "A party wishing to commence an arbitration under these Rules (the "Claimant") shall file with the Registrar a Notice of Arbitration which shall include: [...] e. a brief statement describing the nature and circumstances of the dispute, specifying the relief claimed and, where possible, an initial quantification of the claim amount [...]". 
Las leyes de arbitraje regulan las causales de nulidad de los laudos arbitrales emitidos en su jurisdicción. La gran mayoría de ellas establecen como una causal para anular un laudo arbitral, que el laudo se refiera a una diferencia no sometida a arbitraje, o contenga decisiones que exceden de los términos del compromiso o de la cláusula compromisoria, lo que se ha denominado exceso de poder $^{60}$, una causal casi idéntica a la prescrita por el artículo 31 literal d) de la $\mathrm{LAM}^{61}$.

De igual manera, la Convención sobre el Reconocimiento y la Ejecución de las Sentencias Arbitrales Extranjeras de (Convención de Nueva York) ${ }^{62}$ establece al llamado exceso de poder o vicio de incongruencia, como una causal para denegar el reconocimiento y ejecución de un laudo arbitral ${ }^{63}$.

De la investigación realizada no hemos encontrado ninguna sentencia en que se haya anulado un laudo arbitral o se haya denegado su ejecución porque el tribunal arbitral otorgó más allá

60. Véase, Ley Modelo de CNUDMI, Art. 34.

Art. 34.- "La petición de nulidad como único recurso contra un laudo arbitral. 1) Contra un laudo arbitral sólo podrá recurrirse ante un tribunal mediante una petición de nulidad conforme a los párrafos 2) y 3) del presente artículo. 2) El laudo arbitral sólo podrá ser anulado por el tribunal indicado en el artículo 6 cuando: [...] b) el tribunal compruebe: i) que, según la ley de este Estado, el objeto de la controversia no es susceptible de arbitraje; [...]; Ley de Arbitraje Federal, N. 53, Sección 10(a)(4): “In any of the following cases the United States court in and for the district wherein the award was made may make an order vacating the award upon the application of any party to the arbitration: [...](4) Where the arbitrators exceeded their powers, or so imperfectly executed them that a mutual, final, and definite award upon the subject matter submitted was not made"; Ley de Arbitraje, N. 55, Art. 68(2)(b): "A party to arbitral proceedings may (upon notice to the other parties and to the tribunal) apply to the court challenging an award in the proceedings on the ground of serious irregularity affecting the tribunal, the proceedings or the award. [...] (2) Serious irregularity means an irregularity of one or more of the following kinds which the court considers has caused or will cause substantial injustice to the applicant [...] (b) the tribunal exceeding its powers (otherwise than by exceeding its substantive jurisdiction".

61. Ley de Arbitraje y Mediación (LAM), Art. 31(d), RO No. 417, 14/12/2006.

Art. 31(d). - "Cualquiera de las partes podrá intentar la acción de nulidad de un laudo arbitral, cuando: d) El laudo se refiera a cuestiones no sometidas al arbitraje o conceda más allá de lo reclamado [...]".

62. La Convención de Nueva York (1958) ha sido ratificada por 159 Estados, véase, $<$ goo.gl/3YdB7w>.

63. Convención de Nueva York (1958), Art. V(1)(c).

Art. V(1)(c). - "Sólo se podrá denegar el reconocimiento y la ejecución de la sentencia, a instancia de la parte contra la cual es invocada, si esta parte prueba ante la autoridad competente del país en que se pide el reconocimiento y la ejecución: [...] c) Que la sentencia se refiere a una diferencia no prevista en el compromiso o no comprendida en las disposiciones de la cláusula compromisoria, o contiene decisiones que exceden de los términos del compromiso o de la cláusula compromisoria; no obstante, si las disposiciones de la sentencia que se refieren a las cuestiones sometidas al arbitraje pueden separarse de las que no han sido sometidas al arbitraje, se podrá dar reconocimiento y ejecución a las primeras $[\ldots] "$. 
del monto fijado como cuantía. Las cortes de manera reiterada se han referido a la excepcionalidad de las causales de nulidad y a la deferencia que se debe otorgar a las decisiones de los tribunales arbitrales.

Las cortes en procesos de anulación o ejecución de laudos, se han enfrentado a varias alegaciones relacionadas a la valoración de daños y vicios de exceso o incongruencias, todas ellas infructuosas. Por ejemplo, las cortes estadounidenses han desestimado como un vicio de exceso de poder en la emisión del laudo, una serie de argumentos y han otorgado una gran deferencia a las decisiones de los tribunales arbitrales: (i) la supuesta falta de autoridad del tribunal para otorgar como indemnización honorarios de abogados ${ }^{64}$; (ii) inclusión de una indemnización por daño futuro no prevista en el contrato ${ }^{65}$; (iii) escribió de nuevo el contrato cuando aplicó una responsabilidad limitada a todas las pérdidas e impuso una sanción en forma de honorarios de los abogados ${ }^{66}$; (iv) los árbitros de oficio determinaron que existió una novación ${ }^{67}$; (v) orden de cumplimiento específico ${ }^{68}$ y; (vi) revisó el contrato a pesar de que la condición suspensiva para su nacimiento no se verificó y estableció un esquema dual de precio ${ }^{69}$.

De igual manera, las cortes españolas han rechazado, en varios casos, las alegaciones de exceso o vicio de incongruencia en contra de laudos arbitrales. El Tribunal Superior de Justicia de Madrid, rechazó el argumento de que el Tribunal arbitral había excedido sus facultades por condenar al fiador solidario al pago de las cuotas cuyo vencimiento se encontraba pendiente, en caso de que las mismas no sean pagadas en las fechas acordadas. Este Tribunal consideró que, respetando el principio de intervención mínima, lo ordenado por el tribunal arbitral no excede sus facultades, sino que se ajusta a las mismas por estar íntimamente vin-

\footnotetext{
64. Véase, Dastime Group Limited, et al. v. Moonvale Investments Limited, et al., 17-cv-01859-JSW.

65. Véase, OJSC Ukrnafta v. Carpatsky Petroleum Corp., et al., H-09-891.

66. Véase, Century Indemnity Company, et al. v. Axa Belgium, 11 Civ. 7263(JMF).

67. Véase, Sei Societa Esplosivi Industriali SPA v. L-3 Fuzing and Ordnance Systems, INC., 11-149RGA.

68. Véase, Four Seasons Hotels and Resorts B.V. et al. v. Consorcio Barr S.A., 04-20673-CIV-MOOREISIMONT.

69. Véase, Gas Natural Aprovisionamientos SDG S.A. v. Atlantic LNG Company of Trinidad and Tobago, 08 Civ. 1109 (DLC).
} 
culadas con la pretensión principal ${ }^{70}$. Otros tribunales de otras regiones de España han seguido este ejemplo de mínima intervención rechazando argumentos relacionados con el vicio de ultra y extra petita ${ }^{71}$.

Asimismo, otras cortes en distintas jurisdicciones también han decidido no anular laudos arbitrales ni negar su ejecución, por esta causal. Las cortes inglesas rechazaron argumentos como: (i) exceso de poder por otorgar intereses ${ }^{72}$; (ii) otorgar una reparación sobre disputas nacidas después de la solicitud de arbitraje, relacionadas con la terminación del contrato ${ }^{73}$. Por su parte, la Corte Superior de Singapur, jurisdicción muy activa en arbitraje, también rechazó alegaciones sobre exceso de poder en la determinación de los daños realizado por el tribunal arbitral ${ }^{74}$.

Finalmente, las cortes chilenas, relevantes para nuestro análisis porque la cláusula modelo de arbitraje internacional en Ecuador establece como sede Santiago de Chile, también han sido renuentes a anular laudos arbitrales, por ejemplo, en el caso Productos Naturales de la Sabana S.A., la Corte de Apelaciones rechazó el argumento de que el tribunal arbitral modificó el contrato y condenó al accionante al pago de las $\operatorname{costas}^{75}$.

\section{El Problema de los costos arbitrales}

Otra causa de la problemática práctica descrita en este artículo, son los costos arbitrales, los cuales se fijan de acuerdo a la cuantía y obligan al actor a estimar sus daños, de manera anticipada, en el momento de la presentación de la demanda, momento

70. Tribunal Superior de Justicia de Madrid, D. Dionisio c. Errementari S.L., STSJ M 6565/2015.

71. Véase, Tribunal Superior de Justicia de la Región de Murcia, D. Nemesio, D. Roberto y D. Sixto c. El Pozo Alimentacion S.A., STSJ MU 584/2014; y, Tribunal Superior de Justicia del País Vasco, France Telecom S.A., Orange S.A., Atlas Services Nederland B.V. y France Telecom España S.A. c. Euskaltel S.A., ATSJ PV 2/2012.

72. House of Lords, Lesotho Highlands Development Authority v. Impregilo Spa, UKHL 43.

73. High Court, Honeywell International Middle East Limited v. Meydan Group LLC, HT-12-372.

74. High Court, Galsworthy Ltd of the Republic of Liberia v. Glory Wealth Shipping Pte Ltd., SGHC 304.

75. Primera Sala de la Corte de Apelaciones de Santiago, Productos Naturales de la Sabana S.A., Rol No. 6975- 2012, 29/04/2014. 
en que inicia el procedimiento arbitral en Ecuador. La realidad es que en casos complejos es difícil calcular en esa instancia el monto al que ascenderán los perjuicios; por lo tanto, sería apropiado que la cuantía sea estimada, como sucede en la legislación comparada.

Los centros más relevantes de arbitraje en Ecuador establecen, en sus reglamentos, normas adecuadas que permiten reliquidar los costos arbitrales en el caso de que la cuantía final sea superior a la inicial fijada en la demanda. Esto corrobora lo afirmado respecto a que la cuantía fijada no puede ser un limitante al derecho de reparación, y que otorgar un monto mayor -si este corresponde a las pretensiones planteadas- no puede ser una causal de nulidad por vicio de ultra petita. Sin embargo, estas normas son totalmente desconocidas e inaplicadas en nuestro sistema y de hecho se ven todo el tiempo casos en los cuales los árbitros reducen la indemnización al monto fijado en la cuantía.

El Reglamento de Arbitraje del Centro de Arbitraje y Mediación de la Cámara de Comercio de Quito, al respecto establece lo siguiente:

Costos de Arbitraje.- Por el servicio de arbitraje el Centro cobrará los costos respectivos. Para tal efecto, el Directorio de la Cámara de Comercio de Quito aprobará una tabla de tarifas que será anexo al presente reglamento y que por tanto se constituye en parte integrante del mismo. En caso de cuantía indeterminada el valor será el constante en la tabla de tarifas vigente, sin perjuicio de que el tribunal reliquide estos costos en el caso que de la cuantía del laudo se desprenda un valor superior. Así mismo, el tribunal ordenará la reliquidación de costos de arbitraje en el caso de que la cuantía del laudo sea superior a aquella sobre la cual se cancelaron los costos al inicio del proceso. Una vez reliquidados los costos, el actor deberá consignar la diferencia, sin perjuicio de que en laudo se le condene al demandado al pago de los costos del arbitraje. De lo contrario el Centro se reserva el derecho de no expedir copias certificadas del proceso, así como tampoco tramitar el desglose de documentos ${ }^{76}$.

76. Reglamento del Centro de Arbitraje y Mediación de la Cámara de Comercio de Quito, Art. 70. 
Igualmente, el reglamento de arbitraje del Centro de Arbitraje y Mediación de la Cámara de Comercio Ecuatoriano Americana (AMCHAM), dispone en forma similar:

Por el servicio de arbitraje el CAM cobrará los costos respectivos. Para tal efecto, el Directorio del CAM aprobará un tarifario que se anexa al presente Reglamento y que por lo tanto constituye parte integrante del mismo. El costo del arbitraje se calculará en base a la cuantía de la demanda. En caso de cuantía indeterminada el valor que se cobrará será el determinado en el tarifario aprobado por el Directorio del CAM. En los casos en que la cuantía pueda ser determinable, el Director o en su defecto el tribunal arbitral, determinará la cuantía de la controversia, y por lo tanto, fijará el costo del arbitraje y quien debe asumirlo. Así mismo, se ordenará la reliquidación de costos de arbitraje en el caso de que la cuantía del laudo sea superior a aquella sobre la cual se cancelaron los costos al inicio del proceso, hecho que no constituirá ni ultra ni plus petita (énfasis añadido) ${ }^{77}$.

Asimismo, el Reglamento del Centro de Arbitraje y Conciliación de la Cámara de Comercio de Guayaquil, regula lo siguiente:

El Tribunal podrá, en cualquier estado de la causa, reliquidar el arancel por arbitraje en caso que la cuantía se modifique o si la complejidad del caso así lo amerita. Si cualquiera de las partes presentare impugnación a la reliquidación hecha por el tribunal, será resuelta por el Consejo Asesor. No se proseguirá la sustanciación de un arbitraje sin la cancelación oportuna del costo del arbitraje según la reliquidación debidamente ordenada por el Tribunal o por el Consejo Asesor, según el caso $^{78}$.

Por lo expuesto, los propios reglamentos de arbitraje autorizan a los árbitros a otorgar un monto mayor al fijado en la demanda o reconvención como cuantía. El reglamento de arbitraje de la AMCHAM, además, establece que esta determinación no

77. Reglamento del Centro de Arbitraje y Mediación de la Cámara de Comercio Ecuatoriano Americana, Art. 67.

78. Reglamento del Centro de Arbitraje y Conciliación de la Cámara de Comercio de Guayaquil, Art. 64. 
puede ser considerado como ultra petita. Entonces, no existe una justificación real, desde el punto de vista económico, para que, en la práctica arbitral, los tribunales vean a la cuantía como un limitante a los derechos de las partes.

\section{Conclusiones y SOluciones}

La cuantía como requisito a la demanda nace de los códigos de procedimiento civil, como una forma para determinar la competencia de los jueces, en procesos de mayor o menor cuantía. Estos procesos tenían diferencias entre sí, principalmente en la posibilidad de interponer ciertos recursos. La figura jurídica de la cuantía está relacionada con las pretensiones del actor, pero no puede ser interpretada como un límite a su derecho de reparación.

La jurisprudencia ecuatoriana en reiteradas ocasiones, ha rechazado las acciones de nulidad de laudos arbitrales que se fundamentan en el vicio de incongruencia ultra petita, cuando se ha evidenciado que los tribunales arbitrales han resuelto sobre la base de los argumentos y pruebas aportadas por las partes. De igual manera, según nuestra jurisprudencia si un tribunal arbitral concede un monto superior al fijado en la demanda por la liquidación de intereses, tampoco se configuraría un vicio ultra petita, debido a que los intereses forman parte de la pretensión reclamada.

Desde el punto de vista del derecho comparado, la cuantía no es un requisito para iniciar un arbitraje. Los centros de arbitraje más reconocidos imponen como requisitos para presentar una solicitud de arbitraje, simplemente, una estimación del monto reclamado, dicha estimación usualmente es diferente a lo ordenado en el laudo arbitral. Tampoco existe jurisprudencia comparada, en la cual los laudos arbitrales hayan sido anulados ni se haya rechazado su ejecución porque el tribunal arbitral otorgó más allá de la cuantía fijada. Seguramente, esto se debe a que la cuantía no se mira como un requisito esencial. 
Por todo lo expuesto, desde nuestra perspectiva existen dos soluciones al problema planteado. La primera, de fácil implementación, es que los árbitros abandonen esta práctica ajena a la naturaleza del arbitraje y apliquen las correspondientes reglas de los reglamentos de arbitraje, para reliquidar los costos arbitrales, en los casos en los cuales las pretensiones del actor o reconviniente, después de la práctica y análisis de la prueba, superen la cuantía fijada en su demanda o reconvención.

La segunda solución, que impone una mayor dificultad, es la necesidad de una reforma legal a la LAM, que, en primer lugar, reconozca la tendencia mundial por la cual el arbitraje inicia con una solicitud o notificación, la demanda se presenta posteriormente cuando el tribunal ya se encuentra constituido y puede determinar sus lineamientos; y, en segundo lugar, elimine la cuantía como un requisito para iniciar un arbitraje. 